\title{
PENGARUH GAYA KEPEMIMPINAN TRANSFORMASIONAL PADA KOMITMEN, KEPUASAN KERJA DAN NIAT PINDAH KERJA DENGAN PERAN MEDIASI KEADILAN DAN KEPERCAYAAN DI RSO PROF. DR. R. SOEHARSO SURAKARTA
}

\author{
Paryanto \\ Program Studi Magister Manajemen Universitas Muhammadiyah Surakarta \\ J1. A.Yani Tromol Pos 1, Pabelan Kartusara, Surakarta 57102
}

\begin{abstract}
Improving the quality of hospital services can not be separated from the role of the various disciplines of health workers in hospitals, including nurses, because most hospital services are nursing services. The purpose of this study was to analyze the effect of transformational leadership style on commitment, job satisfaction and nurses' intent to move RSO Prof. Dr. R. Soeharso Surakarta with the mediating role of justice and trust. The study also is associative causal research that seek causal influence of the variables to be studied. This research was conducted and involved nurses Orthopaedic Hospital Prof. Dr. R. Soeharso Surakarta. The number of samples of this study were 124 nurses Orthopaedic Hospital Orthopedics Prof. Dr. R. Soeharso Surakarta. The results showed that transformational leadership style influence on commitment, job satisfaction and nurses' intent to move RSO Prof. Dr. R. Soeharso Surakarta with the mediating role of justice and trust.
\end{abstract}

Keywords: leadership, commitment, job satisfaction, intention to change job

\begin{abstract}
Abstrak
Peningkatan mutu pelayanan rumah sakit tidak terlepas dari peran berbagai disiplin tenaga kesehatan yang ada di rumah sakit termasuk perawat, karena sebagian besar pelayanan rumah sakit adalah pelayanan keperawatan. Tujuan penelitian ini adalah menganalisis pengaruh gaya kepemimpinan transformasional terhadap komitmen, kepuasan kerja dan niat pindah kerja perawat RSO Prof. Dr. R. Soeharso Surakarta dengan peran mediasi keadilan dan kepercayaan. Penelitian ini bersifat asosiatif kausal yaitu penelitian yang mencari pengaruh sebab akibat dari variabel yang akan diteliti. Penelitian ini dilaksanakan dan melibatkan perawat Rumah Sakit Ortopedi Prof. Dr. R. Soeharso Surakarta. Jumlah sampel penelitian ini sebanyak 124 perawat. Hasil penelitian menunjukkan gaya kepemimpinan transformasional berpengaruh terhadap komitmen, kepuasan kerja dan niat pindah kerja perawat RSO Prof. Dr. R. Soeharso Surakarta dengan peran mediasi keadilan dan kepercayaan.
\end{abstract}

Kata Kunci: kepemimpinan, komitmen, kepuasan kerja, niat pindah kerja 


\section{Pendahuluan}

Manajemen sumber daya manusia (Human Resources Management) adalah bagian dari fungsi manajemen. Jika manajemen menitikberatkan tujuan bersama dengan orang lain, maka manajemen sumber daya manusia memfokuskan pada orang baik sebagai subjek atau pelaku dan sekaligus sebagai objek dari perilaku. Jadi bagaimana mengelola orang-orang dalam organisasi yang direncanakan (planning), diorganisasikan (organizing), dilaksanakan (directing) dan dikendalikan (controlling) agar tujuan yang dicapai organisasi dapat diperoleh hasil yang seoptimal mungkin, efisien dan efektif (Subekhi dan Jauhar, 2012).

Peningkatan mutu pelayanan rumah sakit tidak terlepas dari peran berbagai disiplin tenaga kesehatan yang ada di rumah sakit termasuk perawat, karena sebagian besar pelayanan rumah sakit adalah pelayanan keperawatan. Marquis dan Huston (2010) menyampaikan bahwa kualitas pelayanan keperawatan tidak hanya tergantung dari personel keperawatan saja tetapi juga tergantung dari dukungan pihak manajerial malalui fungsi manajemennya yang dimulai dari perencanaan, pengorganisasian, pengarahan dan pengawasan, sehingga mampu menciptakan organisasi yang memungkinkan pekerja tumbuh, meningkatkan motivasi dan produktivitas, menunjukan penghargaan yang positif terhadap pekerja, mengakui prestasi serta mendorong tercapainya kepuasan kerja. Kepuasan kerja perawat walaupun diyakini sangat menentukan terbentuknya kepuasan pasien yang berdampak besar terhadap mutu pelayanan keperawatan, namun belum semua rumah sakit mampu menciptakan suasana yang memotivasi dan meningkatkan produktivitas (Bustami, 2011).

Kepemimpinan merupakan kunci utama dalam manajemen yang memainkan peran penting dan strategis dalam kelangsungan hidup suatu perusahaan. Rivai (2004), menjelaskan bahwa kepemimpinan adalah proses mempengaruhi atau memberi contoh kepada pengikutpengikutnya lewat proses komunikasi dalam upaya mencapai tujuan organisasi. Lebih lanjut lagi Rivai (2004) mengatakan bahwa pemimpin merupakan pencetus tujuan, merencanakan, mengorganisasikan, menggerakkan dan mengendalikan seluruh sumber daya yang dimiliki sehingga tujuan perusahaan dapat tercapai secara efektif dan efisien. Oleh sebab itu pemimpin suatu organisasi perusahaan dituntut untuk selalu mampu menciptakan kondisi yang mampu memuaskan karyawan dalam bekerja sehingga diperoleh karyawan yang tidak hanya mampu bekerja akan tetapi juga bersedia bekerja kearah pencapaian tujuan perusahaan. Namun dalam menjalankan kepemimpinan dalam sebuah perusahaan, para pemimpin bisa memiliki gaya yang berbeda-beda dalam menjalankan gaya kepemimpiannya, diantaranya gaya kepemimpinan tranformasilan. Menurut Benjamin (2006) menjelaskan bahwa kepemimpinan transformasional adalah mampu menginspirasi orang lain untuk melihat masa depan dengan optimis, memperoyeksikan visi yang ideal, dan mampu mengkomunikasikan bawahan bahwa visi dan misi tersebut dapat dicapai.

Gaya kepemimpinan membantu perusahaan untuk semakin berkembang yaitu dengan meningkatkan komitmen organisasional karyawan. Menurut Oei (2010) komitmen organisasional (organizational commitment) adalah kekuatan relatif pengenalan pada keterlibatan dari dalam diri seorang individu dalam organisasi tertentu. Komitmen merupakan dedikasi atau pengabdian seseorang terhadap pekerjaannya dan karyawan memandangnya sebagai kebutuhan dan sangat penting dalam hidupnya. Komitmen mencerminkan keinginan pegawai untuk selalu terlibat dalam kegiatan-kegiatan di organisasinya. Komitmen organisasional yang tinggi biasanya menyebabkan seorang pekerja memiliki rasa memihak yang tinggi pada suatu perusahaan. Oei (2010) menjelaskan bahwa ada beberapa hal yang dapat mempengaruhi 
komitmen organisasional, antara lain: lama bekerja, kepercayaan, rasa percaya diri, kredibilitas, dan pertanggungjawaban.

Pemimpin yang efektif adalah pemimpin yang mengakui kekuatankekuatan penting yang terkandung dalam individu. Setiap individu memiliki kebutuhan dan keinginan yang berbeda-beda. Setiap individu memiliki tingkat keahlian yang berbeda-beda pula. Pemimpin harus fleksibel dalam pemahaman segala potensi yang dimiliki oleh individu dan berbagai permasalahan yang dihadapai individu tersebut. Dengan melakukan pendekatan tersebut, pemimpin dapat menerapkan segala peraturan dan kebijakan organisasi serta melimpahkan tugas dan tanggung jawab dengan tepat. Hal ini sejalan dengan usaha untuk menumbuhkan komitmen organisasi dari diri karyawan. Sehingga pemimpin nantinya dapat meningkatkan kepuasan karyawan terhadap pekerjaannya serta dapat meningkatkan kinerja karyawan dengan lebih efektif.

Rumah Sakit Ortopedi Prof. Dr. R. Soeharso Surakarta adalah rumah sakit tipe A Pendidikan Kolegium Ilmu Ortopedi dan Traumatologi Indonesia yang merupakan rujukan nasional. Untuk meningkatkan kepuasan pelanggan atau pemakai jasanya, salah satu misi Rumah Sakit Ortopedi Prof. Dr. R. Soeharso Surakarta adalah menyelenggarakan pelayanan Ortopedi Traumatologi dan Rehabilitasi Medik yang paripurna berorientasi pada kebutuhan dan kesehatan pasien, dan berkualitas, serta terjangkau oleh seluruh lapisan masyarakat. Oleh karena itu, perlu untuk dilakukan pengukuran terhadap komitmen, kepuasan kerja dan niat pindah kerja pada perawat melalui peningkatan dan pemanfaatan sumber daya yang seoptimal mungkin, sehingga menjadi sumber daya manusia yang professional.

\section{Tinjauan Pustaka}

\section{Gaya Kepemimpinan Tranfor- masional}

Menurut Benjamin (2006) kepemimpinan transformasional adalah mampu menginspirasi orang lain untuk melihat masa depan dengan optimis, memperoyeksikan visi yang ideal, dan mampu mengkomunikasikan bawahan bahwa visi dan misi tersebut dapat dicapai.

Tucker dan Lewis (2004) mendefinisikan kepemimpinan transformasional sebagai pola kepemimpinan yang dapat memotivasi karyawan dengan cara membawa pada citacita dan nilai-nilai tinggi untuk mencapai visi misi organisasi yang merupakan dasar untuk membentuk kepercayaan terhadap pimpinan. Kepemimpinan transformasional merupakan induk kepemimpinan transaksional dan memberikan kerangka referensi pada organisasi.

\section{Komitmen}

Menurut Mathis dan Jackson (2001) komitmen organisasi merupakan tingkat kepercayaan dan penerimaan karyawan terhadap tujuan organisasi dan mempunyai keinginan untuk tetap ada dalam organisasi tersebut. Organizational Commitment juga didefinisikan sebagai kekuatan identifikasi dan keterlibatan individual dalam organisasi tertentu (Mowday, et al. 1982). Individual dengan Organizational Commitment yang tinggi dikarakterkan dengan penerimaan dan kepercayaan yangtinggi dalam nilai dan tujuan organisasi, keinginan untuk berusaha sekuat tenaga demi kepentingan organisasi, dan keinginan yang kuat untuk mempertahankan keanggotaannya dalam organisasi (Mowday et al., 1982). Wiener (2000) mendefinisikan Organizational Commitment sebagai dorongan dari dalam diriindividu untuk berbuat sesuatu agar dapat menunjang keberhasilan organisasi sesuai dengan tujuan dan meletakkan kepentingan organisasi di atas kepentinganpribadinya.

\section{Kepuasan Kerja Perawat}

Robbins (2008) mendefinisikan kepuasan kerja sebagai sikap umum terhadap pekerjaan seseorang, yang menunjukkan perbedaan antara jumlah penghargaan yang diterima pekerja dan jumlah yang mereka yakini seharusnya mereka terima. Mathis 
dan Jackson (2009) menyatakan bahwa kepuasan kerja adalahkeadaan emosi yang positif darimenegevaluasi pengalaman kerjaseseorang. Sunyoto (2012) menjelaskan bahwa kepuasan kerja adalah keadaan emosional yang menyenangkan atau tidak menyenangkan di mana para karyawan memandang pekerjaannya". Mangkunegara (2009) menyatakan bahwa kepuasan kerja berhubungan dengan variabel-variabel seperti turnover, tingkat absensi, umur, tingkat pekerjaan, dan ukuran organisasi perusahaan. Sunyoto (2012) mengemukakankepuasan kerja berhubungan denganabsensi, perputaran tenaga kerja,produktifitas, kecelakaan kerja, labour turnover, dan sebagainya.

\section{Niat Pindah Kerja}

Niat pindah kerja (turnover intention) diartikan sebagai keinginan individu keluar dari perusahaan. Turnover mengarah pada kenyataan akhir yang dihadapi perusahaan berupa jumlah karyawan yang meninggalkan perusahaan pada periode tertentu. Menurut Elci et al., (2007), turnover intention adalah kemungkinan bahwa seseorang akan meninggalkan pekerjaannya di masa datang. Mathis \& Jackson (2001) mendefinisikan turnover sebagai suatu proses dimana tenaga kerja meninggalkan organisasi dan harus ada yang menggantikannya. Turnover yang tinggi menimbulkan biaya yang tinggi. Kenaikan biaya ini diakibatkan produktivitas yang hilang, waktu pelatihan dan waktu pemilihan tenaga kerja baru yang bertambah, hilangnya efisiensi kerja dan biaya tidak langsung lainnya. Turnover intention dalam penelitian ini adalah keinginan karyawan untuk berpindah pekerjaan atau mencari pekerjaan di perusahaan lain yang lebih baik.

\section{Keadilan}

Menurut Griffin dan Moorhead (2010) keadilan organisasi merupakan fenomena penting yang baru-baru ini telah diperkenalkan ke dalam studi organisasi. Keadilan dapat dibahas dari berbagai perspektif, termasuk motivasi, kepemimpinan, dan dinamika kelompok. keadilan organisasi adalah suatu proses kognitif dan afektif individu untuk menilai perlakuan organisasi terhadap dirinya dalam hal upaya yang adil untuk mendapatkan hasil, proses untuk memperoleh hasil itu dilakukan secara adil atau tidak, serta bentuk-bentuk perlakuan interpersonal dan informasional terhadap masing-masing karyawannya.

\section{Kepercayaan}

Menurut Robbins dan Judge (2008) kepercayaan adalah suatu harapan positif bahwa orang lain tidak akan bertindak secara oportunistik. Istilah oportunistik merujuk pada risiko di dalam hubungan berbasis kepercayaan. Berdasarkan Demircan dan Ceylan, yang dikutip oleh Toprak (2006) kepercayaan adalah hal penting dalam semua hubungan di sebuah organisasi, khususnya hubungan antara staf dan pimpinan karyawan. Kepercayaan merupakan sebuah komponen penting dari kehidupan yang memiliki konsekuensi yang menguntungkan staf dan organisasi. Hal ini diakui sebagai faktor yang menjamin karyawan bergerak menuju tujuan bersama dan bekerja sama dalam mengejar tujuan tersebut. Oleh karena itu, pimpinan perlu memberikan perhatian khusus untuk mengembangkan kepercayaan antara karyawan dan bekerja dengan karyawan yang percaya satu sama lain.

\section{Metode Penelitian}

Penelitian ini termasuk dalam kategori penelitian ex-post facto yaitu suatu penelitian yang dilakukan untuk meneliti peristiwa yang telah terjadi dan kemudian merunut ke belakang untuk mengetahui faktor-faktor yang dapat menyebabkan timbulnya kejadian tersebut (Sugiyono, 2009). Penelitian ini juga bersifat asosiatif kausal yaitu penelitian yang mencari pengaruh sebab akibat dari variabel yang akan diteliti.Berdasarkan pada waktu yang digunakan dalam penelitian ini adalah studi cross sectional. Studi Cross Sectional yaitu studi untuk mengetahui hubungan komparatif beberapa subjek yang 
diteliti. Umumnya merupakan tipe studi satu tahap yang datanya berupa beberapa subjek pada waktu tertentu. Rancangan cross sectional merupakan rancangan penelitian yang pengukuran atau pengamatanya dilakukan secara simultan pada satu saat atau sekali waktu (Hidayat, 2007).

Populasi dalam penelitian ini adalah seluruh perawat Rumah Sakit Ortopedi Ortopedi Prof. Dr. R. Soeharso Surakarta yang bertugas dipelayanan yang berjumlah 180 orang. Jumlah sampel penelitian ini sebanyak 124 perawat Rumah Sakit Ortopedi
Ortopedi Prof. Dr. R. Soeharso Surakarta yang dirasa cukup mewakili populasi yang diteliti. Jumlah sampel penelitian ini sebanyak 124 perawat Rumah Sakit Ortopedi Ortopedi Prof. Dr. R. Soeharso Surakarta yang dirasa cukup mewakili populasi yang diteliti.

Pengujian hipotesis dalam penelitian ini untuk membuktikan pengaruh gaya kepemimpinan pada komitmen, kepuasan kerja dan niat pindah kerja perawat dengan peran medias keadilan dan kepercayaan yang dilakukan dengan menggunakan analisis regresi dengan variabel mediasi

\section{Hasil Dan Pembahasan}

\section{Pengaruh Gaya Kepemimpinan Transformasional terhadap Komitmen dengan Peran Mediasi Keadilan}

Tabel 1. Hasil Pengujian Pengaruh Gaya Kepemimpinan Transformasional terhadap Komitmen dengan Peran Mediasi Keadilan

\begin{tabular}{lc}
\hline \multicolumn{1}{c}{ Regresi Variabel } & Sig. \\
\hline Langkah $1: \mathrm{X} \rightarrow \mathrm{Y}_{1}$ & 0,000 \\
Gaya Kepemimpinan Tranformasional $\rightarrow$ Komitmen & \\
Langkah $2: \mathrm{X} \rightarrow \mathrm{Z}_{1}$ & 0,000 \\
Gaya Kepemimpinan Tranformasional $\rightarrow$ Keadilan & \\
Langkah $3: \mathrm{Z}_{1} \rightarrow \mathrm{Y}_{1}$ & 0,001 \\
Keadilan $\rightarrow$ Komitmen & \\
Langkah $4: \mathrm{X} \rightarrow \mathrm{Z}_{1} \rightarrow \mathrm{Y}_{1}$ & \\
Gaya Kepemimpinan Tranformasional $\rightarrow$ Keadilan $\rightarrow$ Komitmen & 0,013 \\
\hline
\end{tabular}

Sumber: data primer diolah, 2015

Pada Tabel 1 menunjukkan hasil perhitungan pengaruh gaya kepemimpinan transformasional terhadap komitmen dengan peran mediasi keadilan diketahui bahwa hasil pada langkah 1, 2 dan 3 telah memenuhi asumsi bahwa keadilan dapat dijadikan sebagai variabel mediasi terhadap komitmen.

Hasil perhitungan pada langkah 4 menunjukkan bahwa variabel keadilan mampu memediasi variabel gaya kepemimpinan tranformasional terhadap komitmen dengan nilai signifikansi 0,013. Sebagaimana ketentuan apabila hasilnya signifikan tetapi dengan derajat yang lebih kecil, maka diketahui sebagai mediasi sebagian (partial mediation). Apabila hasilnya tidak signifikan, maka diketahui sebagai mediasi penuh (full mediation) (Baron dan Kenny, 1986 dalam Newson, 2012). Maka dapat disimpulkan bahwa $\mathrm{H}_{0}$ ditolak dan $\mathrm{H}_{a}$ diterima, artinya gaya kepemimpinan transformasional berpengaruh terhadap komitmen dengan peran mediasi keadilan pada kategori partial mediation, sehingga $\mathrm{H}_{1}$ yang menyatakan bahwa gaya kepemimpinan transformasional berpengaruh terhadap komitmen perawat Rumah Sakit Ortopedi Prof. Dr. R. Soeharso Surakarta dengan peran mediasi keadilan terbukti kebenarannya. 


\section{Pengaruh Gaya Kepemimpinan Transformasional terhadap Kepuasan Kerja dengan Peran Mediasi Keadilan}

Tabel 2. Hasil Pengujian untuk Pengaruh Gaya Kepemimpinan Transformasional terhadap Kepuasan

\begin{tabular}{lc}
\multicolumn{2}{c}{ Kerja dengan Peran Mediasi Keadilan } \\
\hline \multicolumn{1}{c}{ Regresi Variabel } & Sig. \\
\hline Langkah $1: \mathrm{X} \rightarrow \mathrm{Y}_{2}$ & 0,000 \\
Gaya Kepemimpinan Tranformasional $\rightarrow$ Kepuasan Kerja & \\
Langkah $2: \mathrm{X} \rightarrow \mathrm{Z}_{1}$ & 0,000 \\
Gaya Kepemimpinan Tranformasional $\rightarrow$ Keadilan & \\
Langkah 3: $\mathrm{Z}_{1} \rightarrow \mathrm{Y}_{2}$ & 0,000 \\
Keadilan $\rightarrow \mathrm{Kepuasan}_{2}$ Kerja & \\
Langkah $4: \mathrm{X} \rightarrow \mathrm{Z}_{1} \rightarrow \mathrm{Y}_{2}$ & 0,000 \\
Gaya Kepemimpinan Tranformasional $\rightarrow$ Keadilan $\rightarrow$ Kepuasan & \\
\hline
\end{tabular}

Sumber: data primer diolah, 2015

Pada Tabel 2 menunjukkan hasil perhitungan pengaruh gaya kepemimpinan transformasional terhadap kepuasan kerja dengan peran mediasi keadilan diketahui bahwa hasil pada langkah 1, 2 dan 3 telah memenuhi asumsi bahwa keadilan dapat dijadikan sebagai variabel mediasi terhadap kepuasan kerja.

Hasil perhitungan pada langkah 4 menunjukkan bahwa variabel keadilan mampu memediasi variabel gaya kepemimpinan tranformasional terhadap kepuasan kerja dengan nilai signifikansi 0,000 . Apabila hasilnya signifikan tetapi dengan derajat yang lebih kecil, maka diketahui sebagai mediasi sebagian (partial mediation). Namun apabila hasilnya tidak signifikan, maka diketahui sebagai mediasi penuh (full mediation) (Baron dan Kenny, 1986 dalam Newson, 2012). Maka dapat disimpulkan bahwa $\mathrm{H}_{0}$ ditolak dan $\mathrm{H}_{\mathrm{a}}$ diterima, artinya gaya kepemimpinan transformasional berpengaruh terhadap kepuasan kerja dengan peran mediasi keadilan pada kategori partial mediation, sehingga $\mathrm{H}_{2}$ yang menyatakan bahwa gaya kepemimpinan transformasional berpengaruh terhadap kepuasan kerja perawat Rumah Sakit Ortopedi Prof. Dr. R. Soeharso Surakarta dengan peran mediasi keadilan terbukti kebenarannya.

\section{Pengaruh Gaya Kepemimpinan Transformasional terhadap Niat Pindah Kerja dengan Peran Mediasi Keadilan}

Tabel 3. Hasil Pengujian untuk Pengaruh Gaya Kepemimpinan Transformasional terhadap Kepuasan Kerja dengan Peran Mediasi Keadilan

\begin{tabular}{lc}
\hline \multicolumn{1}{c}{ Regresi Variabel } & Sig. \\
\hline Langkah 1 $\mathrm{X} \rightarrow \mathrm{Y}_{3}$ & 0,003 \\
Gaya Kepemimpinan Tranformasional $\rightarrow$ Niat Pindah Kerja & \\
Langkah $2: \mathrm{X} \rightarrow \mathrm{Z}_{1}$ & 0,000 \\
Gaya Kepemimpinan Tranformasional $\rightarrow$ Keadilan & \\
Langkah $3: \mathrm{Z}_{1} \rightarrow \mathrm{Y}_{3}$ & 0,000 \\
Keadilan $\rightarrow$ Niat Pindah Kerja & \\
Langkah $4: \mathrm{X} \rightarrow \mathrm{Z}_{1} \rightarrow \mathrm{Y}_{3}$ & 0,142 \\
Gaya Kepemimpinan Tranformasional $\rightarrow$ Keadilan $\rightarrow$ Niat Pindah & \\
\hline
\end{tabular}

Sumber: data primer diolah, 2015 
Tabel 3 menunjukkan hasil perhitungan pengaruh gaya kepemimpinan transformasional terhadap niat pindah kerja dengan peran mediasi keadilan diketahui bahwa hasil pada langkah 1, 2 dan 3 telah memenuhi asumsi bahwa keadilan dapat dijadikan sebagai variabel mediasi terhadap kepuasan kerja.

Hasil perhitungan pada langkah 4 menunjukkan bahwa variabel keadilan mampu memediasi variabel gaya kepemimpinan tranformasional terhadap niat pindah dengan nilai signifikansi 0,142 . Apabila hasilnya signifikan tetapi dengan derajat yang lebih kecil, maka diketahui sebagai mediasi sebagian (partial mediation). Namun apabila hasilnya tidak signifikan, maka diketahui sebagai mediasi penuh (full mediation) (Baron dan Kenny, 1986 dalam Newson, 2012). Maka dapat disimpulkan bahwa $\mathrm{H}_{0}$ ditolak dan $\mathrm{H}_{\mathrm{a}}$ diterima, artinya gaya kepemimpinan transformasional berpengaruh terhadap niat pindah kerja dengan peran mediasi keadilan pada kategori full mediation, sehingga $\mathrm{H}_{3}$ yang menyatakan bahwa gaya kepemimpinan transformasional berpengaruh terhadap niat pindah kerja perawat Rumah Sakit Ortopedi Prof. Dr. R. Soeharso Surakarta dengan peran mediasi keadilan terbukti kebenarannya.

\section{Pengaruh Gaya Kepemimpinan Transformasional terhadap Komitmen dengan Peran Mediasi Kepercayaan}

Tabel 4. Hasil Pengujian untuk Pengaruh Gaya Kepemimpinan Transformasional terhadap Komitmen dengan Peran Mediasi Kepercayaan

\begin{tabular}{|c|c|}
\hline Regresi Variabel & Sig. \\
\hline $\begin{array}{l}\text { Langkah } 1: \mathrm{X} \rightarrow \mathrm{Y}_{1} \\
\text { Gaya Kepemimpinan Tranformasional } \rightarrow \text { Komitmen }\end{array}$ & 0,000 \\
\hline $\begin{array}{l}\text { Langkah } 2: X \rightarrow Z_{2} \\
\text { Gaya Kepemimpinan Tranformasional } \rightarrow \text { Kepercayaan }\end{array}$ & 0,000 \\
\hline $\begin{array}{l}\text { Langkah } 3: \mathrm{Z}_{2} \rightarrow \mathrm{Y}_{1} \\
\text { Kepercayaan } \rightarrow \text { Komitmen }\end{array}$ & 0,000 \\
\hline $\begin{array}{l}\text { Langkah } 4: X \rightarrow Z_{2} \rightarrow Y_{1} \\
\text { Gaya Kep. Tranformasional } \rightarrow \text { Kepercayaan } \rightarrow \text { Komitmen }\end{array}$ & 0,101 \\
\hline
\end{tabular}

Sumber: data primer diolah, 2015

Tabel 4 menunjukkan bahwa hasil perhitungan untuk pengaruh gaya kepemimpinan transformasional terhadap komitmen dengan peran mediasi kepercayaan diketahui bahwa hasil pada langkah 1, 2 dan 3 maka telah memenuhi asumsi bahwa kepercayaan dapat dijadikan sebagai variabel mediasi terhadap komitmen.

Hasil perhitungan pada langkah 4 menunjukkan bahwa variabel kepercayaan mampu memediasi variabel gaya kepemimpinan tranformasional terhadap komitmen dengan nilai signifikansi 0,101. Sebagaimana ketentuan apabila hasilnya signifikan tetapi dengan derajat yang lebih kecil, maka diketahui sebagai mediasi sebagian (partial mediation). Namun apabila hasilnya tidak signifikan, maka diketahui sebagai mediasi penuh (full mediation) (Baron dan Kenny, 1986 dalam Newson, 2012). Maka dapat disimpulkan bahwa $\mathrm{H}_{0}$ ditolak dan $\mathrm{H}_{\mathrm{a}}$ diterima, artinya gaya kepemimpinan transformasional berpengaruh terhadap komitmen dengan peran mediasi kepercayaan pada kategori full mediation, sehingga $\mathrm{H}_{4}$ yang menyatakan bahwa gaya kepemimpinan transformasional berpengaruh terhadap komitmen perawat Rumah Sakit Ortopedi Prof. Dr. R. Soeharso Surakarta dengan peran mediasi kepercayaan terbukti kebenarannya. 


\section{Pengaruh Gaya Kepemimpinan Transformasional terhadap Kepuasan Kerja dengan Peran Mediasi Kepercayaan}

Tabel 5.

Hasil Pengujian untuk Pengaruh Gaya Kepemimpinan Transformasional terhadap Kepuasan Kerja dengan Peran Mediasi Kepercayaan

\begin{tabular}{lc}
\hline \multicolumn{1}{c}{ Regresi Variabel } & Sig. \\
\hline Langkah 1: $\mathrm{X} \rightarrow \mathrm{Y}_{2}$ & 0,000 \\
Gaya Kepemimpinan Tranformasional $\rightarrow$ Kepuasan Kerja & \\
Langkah 2: $\mathrm{X} \rightarrow \mathrm{Z}_{2}$ & 0,000 \\
Gaya Kepemimpinan Tranformasional $\rightarrow$ Kepercayaan & \\
Langkah 3: $\mathrm{Z}_{2} \rightarrow \mathrm{Y}_{2}$ & 0,000 \\
Kepercayaan $\rightarrow \mathrm{Kepuasan}$ Kerja & \\
Langkah 4 $\mathrm{X} \rightarrow \mathrm{Z}_{2} \rightarrow \mathrm{Y}_{2}$ & 0,001 \\
Gaya Kep. Tranformasional $\rightarrow$ Kepercayaan $\rightarrow$ Kepuasan &
\end{tabular}

Sumber: data primer diolah, 2015

Tabel 5 menunjukkan hasil perhitungan untuk pengaruh gaya kepemimpinan transformasional terhadap kepuasan kerja dengan peran mediasi kepercayaan diketahui bahwa hasil pada langkah 1, 2 dan 3 maka telah memenuhi asumsi bahwa kepercayaan dapat dijadikan sebagai variabel mediasi terhadap kepuasan kerja. Hasil perhitungan pada langkah 4 menunjukkan bahwa variabel kepercayaan mampu memediasi variabel gaya kepemimpinan tranformasional terhadap kepuasan kerja dengan nilai signifikansi 0,001. Sebagaimana ketentuan apabila hasilnya signifikan tetapi dengan derajat yang lebih kecil, maka diketahui sebagai mediasi sebagian (partial mediation). Namun apabila hasilnya tidak signifikan, maka diketahui sebagai mediasi penuh (full mediation) (Baron dan Kenny, 1986 dalam Newson, 2012). Maka dapat disimpulkan bahwa $\mathrm{H}_{0}$ ditolak dan $\mathrm{H}_{a}$ diterima, artinya gaya kepemimpinan transformasional berpengaruh terhadap kepuasan kerja dengan peran mediasi kepercayaan pada kategori partial mediation, sehingga $\mathrm{H}_{5}$ yang menyatakan bahwa gaya kepemimpinan transformasional berpengaruh terhadap kepuasan kerja perawat Rumah Sakit Irtopedi Prof. Dr. R. Soeharso Surakarta dengan peran mediasi kepercayaan terbukti kebenarannya.

\section{Pengaruh Gaya Kepemimpinan Transformasional terhadap Niat Pindah Kerja dengan Peran Mediasi Kepercayaan}

Tabel 6. Hasil Pengujian untuk Pengaruh Gaya Kepemimpinan Transformasional terhadap Niat Pindah Kerja dengan Peran Mediasi Kepercayaan

\begin{tabular}{l|c}
\hline \multicolumn{1}{c}{ Regresi Variabel } & Sig. \\
\hline \begin{tabular}{l}
\multicolumn{1}{c}{ Langkah 1 $\mathrm{X} \rightarrow \mathrm{Y}_{3}$} \\
Gaya Kepemimpinan Tranformasional $\rightarrow$ Niat Pindah Kerja
\end{tabular} & 0,003 \\
\hline $\begin{array}{l}\text { Langkah 2: } \mathrm{X} \rightarrow \mathrm{Z}_{2} \\
\text { Gaya Kepemimpinan Tranformasional } \rightarrow \text { Kepercayaan }\end{array}$ & 0,000 \\
\hline $\begin{array}{l}\text { Langkah 3: } \mathrm{Z}_{2} \rightarrow \mathrm{Y}_{3} \\
\text { Kepercayaan } \rightarrow \mathrm{Niat}_{\text {Pindah Kerja }}\end{array}$ & 0,000 \\
\hline $\begin{array}{l}\text { Langkah 4 } \mathrm{X} \rightarrow \mathrm{Z}_{2} \rightarrow \mathrm{Y}_{3} \\
\text { Gaya Kep. Tranformasional } \rightarrow \text { Kepercayaan } \rightarrow \text { Niat Pindah Kerja }\end{array}$ & 0,217 \\
\hline
\end{tabular}

Sumber: data primer diolah, 2015 
Tabel 6. Menunjukkan bahwa hasil perhitungan untuk pengaruh gaya kepemimpinan transformasional terhadap niat pindah kerja dengan peran mediasi kepercayaan diketahui bahwa hasil pada langkah 1, 2 dan 3 maka telah memenuhi asumsi bahwa kepercayaan dapat dijadikan sebagai variabel mediasi terhadap niat pindah kerja.

Hasil perhitungan pada langkah 4 menunjukkan bahwa variabel kepercayaan mampu memediasi variabel gaya kepemimpinan tranformasional terhadap niat pindah kerja dengan nilai signifikansi 0,217. Sebagaimana ketentuan apabila hasilnya signifikan tetapi dengan derajat yang lebih kecil, maka diketahui sebagai mediasi sebagian (partial mediation). Namun apabila hasilnya tidak signifikan, maka diketahui sebagai mediasi penuh (full mediation) (Baron dan Kenny, 1986 dalam Newson, 2012). Maka dapat disimpulkan bahwa $\mathrm{H}_{0}$ ditolak dan $\mathrm{H}_{\mathrm{a}}$ diterima, artinya gaya kepemimpinan transformasional berpengaruh terhadap niat pindah kerja dengan peran mediasi kepercayaan pada kategori partial mediation, sehingga $\mathrm{H}_{6}$ yang menyatakan bahwa gaya kepemimpinan transformasional berpengaruh terhadap niat pindah kerja perawat RSO Prof. Dr. R. Soeharso Surakarta dengan peran mediasi kepercayaan terbukti kebenarannya.

\section{Penutup}

Berdasarkan hasil penelitian tentang pengaruh gaya kepemimpinan transformasional terhadap komitmen, kepuasan dan niat pindah kerja perawat Rumah Sakit Ortopedi Prof. Dr. R. Soeharso Surakarta dengan peran mediasi keadilan dan kepercayaan dapat ditarik kesimpulan sebagai berikut. Gaya kepemimpinan transformasional berpengaruh terhadap komitmen dengan peran mediasi keadilan pada kategori partial mediation, sehingga $\mathrm{H}_{1}$ yang menyatakan bahwa gaya kepemimpinan transformasional berpengaruh terhadap komitmen perawat Rumah Sakit Ortopedi Prof. Dr. R. Soeharso Surakarta dengan peran mediasi keadilan terbukti kebenarannya Gaya kepemimpinan transformasional berpengaruh terhadap kepuasan kerja dengan peran mediasi keadilan pada kategori partial mediation, sehingga $\mathrm{H}_{2}$ yang menyatakan bahwa gaya kepemimpinan transformasional berpengaruh terhadap kepuasan kerja perawat Rumah Sakit Ortopedi Prof. Dr. R. Soeharso Surakarta dengan peran mediasi keadilan terbukti kebenarannya. Gaya kepemimpinan transformasional berpengaruh terhadap niat pindah kerja dengan peran mediasi keadilan pada kategori full mediation, sehingga $\mathrm{H}_{3}$ yang menyatakan bahwa gaya kepemimpinan transformasional berpengaruh terhadap niat pindah kerja perawat Rumah Sakit Ortopedi Prof. Dr. R. Soeharso Surakarta dengan peran mediasi keadilan terbukti kebenarannya. Gaya kepemimpinan transformasional berpengaruh terhadap komitmen dengan peran mediasi kepercayaan pada kategori full mediation, sehingga $\mathrm{H}_{4}$ yang menyatakan bahwa gaya kepemimpinan transformasional berpengaruh terhadap komitmen perawat Rumah Sakit Ortopedi Prof. Dr. R. Soeharso Surakarta dengan peran mediasi kepercayaan terbukti kebenarannya. Gaya kepemimpinan transformasional berpengaruh terhadap kepuasan kerja dengan peran mediasi kepercayaan pada kategori partial mediation, sehingga $\mathrm{H}_{5}$ yang menyatakan bahwa gaya kepemimpinan transformasional berpengaruh terhadap kepuasan kerja perawat Rumah Sakit Ortopedi Prof. Dr. R. Soeharso Surakarta dengan peran mediasi kepercayaan terbukti kebenarannya. Gaya kepemimpinan transformasional berpengaruh terhadap niat pindah kerja dengan peran mediasi kepercayaan pada kategori partial mediation, sehingga $\mathrm{H}_{6}$ yang menyatakan bahwa gaya kepemimpinan transformasional berpengaruh terhadap niat pindah kerja perawat Rumah Sakit Ortopedi Prof. Dr. R. Soeharso Surakarta dengan peran mediasi kepercayaan terbukti kebenarannya.

Adanya berbagai keterbatasan dalam penelitian ini, maka penulis dalam penelitian ini memberikan saran-saran sebagai berikut. 
Penelitian ini diharapkan dapat meningkatkan pemahaman para akademisi terkait dengan konsep komitmen, kepuasan serta niat pindah kerja pada perawat, perawat menjalin kerjasama dengan perawat lain agar terbentuk keadilan dan kepercayaan dalam bekerja. Hal tersebut didasarkan pada keragaman karakteristik yang terdapat dalam penelitian ini yang memberikan perspektif yang berbeda dari penelitian terdahulu. Bagi manajemen rumah sakit diharapkan lebih memperhatikan gaya kepemimpinan yang diimplementasikan pada perawat dengan senantiasa memberikan keadilan dan kepercayaan sesuai kapasitas perawat, menghargai kinerja perawat dengan memberikan tambahan kompensasi yang sesuai, menyediakan tempat kerja yang nyaman, memberikan kesempatan perawat untuk mengembangkan karier serta memberikan kebebasan untuk bekerja sesuai dengan prinsip. 3. Untuk penelitian selanjutnya diharapkan lebih selektif memilih variabel yang berhubungan dengan konsep komitmen, kepuasan serta niat pindah kerja pada perawat dengan menyesuaikan obyek penelitian.

\section{Daftar Pustaka}

Benjamin L. 2006. "Leadership Style and Regulatory Mode: Value from fit?". Organizational Behavior and Hurman Decision Processes.(belum lengkap)

Bustami. 2011. Penjaminan Mutu Pelayanan Kesehatan \& Akseptabilitasnya. Jakarta: Erlangga.

Hidayat, A.A. 2007. Metode Penelitian Kebidanan Dan Tehnik Analisis Data. Surabaya: Salemba.

Marquis dan Huston. 2010. Kepemimpinan dan manajemen keperawatan. Teori dan Aplikasi. Alih bahasa: Widyawati dan Handayani. Jakarta. Edisi 4. EGC.

Mathis, R.L dan Jackson, J.H. 2009. Manajemen Sumber Daya Manusia Buku I. Terjemahan oleh Jimmy Sadeli dan Bayu Prawira Hie. Jakarta: Salemba Empat.

Mangkunegara, A.P. 2009. Manajemen Sumber Daya Manusia Perusahaan. Bandung: PT. Remaja Rosdakarya.

Oei, I. 2010. Riset Sumber Daya Manusia. Jakarta: Penerbit PT. Gramedia.

Robbins, S.P. 2008. Perilaku Organisasi. Edisi kesepuluh. Jakarta: PT Indeks Kelompok Gramedia.

Subekhi A dan Jauhar M. 2012. Pengantar Manajemen Sumber Daya Manusia. Jakarta: Prestasi Pustaka. 